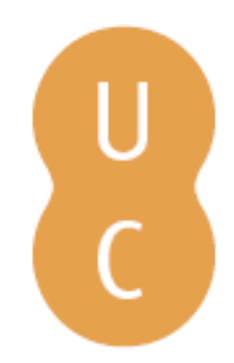

\title{
pommalina
}

\section{Estratigrafia e interpretação estrutural de intervalos sísmicos do setor central da Bacia Lusitânica e na Bacia de Peniche (Portugal)}

\author{
Autor(es): $\quad$ Cumbo, J. M.; Reis, R. Pena dos \\ Publicado por: Imprensa da Universidade de Coimbra \\ URL \\ persistente: URI:http://hdl.handle.net/10316.2/31394 \\ DOI: $\quad$ DOI:http://dx.doi.org/10.14195/978-989-26-0534-0_9 \\ Accessed : $\quad$ 26-Apr-2023 14:33:27
}

A navegação consulta e descarregamento dos títulos inseridos nas Bibliotecas Digitais UC Digitalis, UC Pombalina e UC Impactum, pressupõem a aceitação plena e sem reservas dos Termos e Condições de Uso destas Bibliotecas Digitais, disponíveis em https://digitalis.uc.pt/pt-pt/termos.

Conforme exposto nos referidos Termos e Condições de Uso, o descarregamento de títulos de acesso restrito requer uma licença válida de autorização devendo o utilizador aceder ao(s) documento(s) a partir de um endereço de IP da instituição detentora da supramencionada licença.

Ao utilizador é apenas permitido o descarregamento para uso pessoal, pelo que o emprego do(s) título(s) descarregado(s) para outro fim, designadamente comercial, carece de autorização do respetivo autor ou editor da obra.

Na medida em que todas as obras da UC Digitalis se encontram protegidas pelo Código do Direito de Autor e Direitos Conexos e demais legislação aplicável, toda a cópia, parcial ou total, deste documento, nos casos em que é legalmente admitida, deverá conter ou fazer-se acompanhar por este aviso.

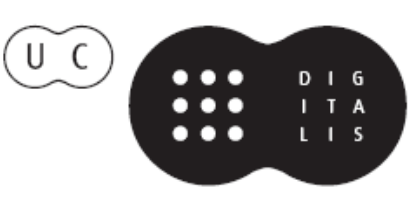





\title{
ESTRATIGRAFIA E INTERPRETAÇÃO ESTRUTURAL DE INTERVALOS SÍSMICOS DO SETOR CENTRAL DA BACIA LUSITÂNICA E NA BACIA DE PENICHE (PORTUGAL)
}

\author{
STRATIGRAPHY AND STRUCTURAL INTERPRETATION OF \\ SEISMIC INTERVALS IN THE CENTRAL SECTOR OF THE \\ LUSITANIAN BASIN AND IN THE PENICHE BASIN (PORTUGAL)
}

J. M. Cumbo ${ }^{1} \&$ R. Pena dos Reis ${ }^{2}$

\begin{abstract}
Resumo - O conjunto das bacias marginais do Atlântico Norte situadas no onshore e no offshore português inclui, entre outras, a Bacia Lusitânica (onshore e offshore raso) e a Bacia de Peniche (offshore profundo). A Bacia Lusitânica aflora em grande parte e, por isso, a informação acumulada é muito vasta; já a Bacia de Peniche é apenas conhecida através de algumas poucas linhas sísmicas publicadas (ALVES et al., 2006). Nas linhas sísmicas e respetivas superfícies estratigráficas interpretadas por vários autores, foram efetuadas mediçôes de espessura dos intervalos sísmicos, a partir de estruturas, cuja influência na sedimentação é provável (núcleos de domos salinos, falhas maiores, etc.). Os dados obtidos foram representados e verifica-se que as unidades sísmicas do Cretácico na Bacia Lusitânica são menos afetadas pela migração do sal e pela atividade das falhas do que as equivalentes da Bacia de Peniche, em que é visível o falhamento das paredes das condutas do sal a condicionar fortemente as espessuras das unidades sísmicas. O Jurássico superior da Bacia Lusitânica mostra também uma influência marcada do falhamento e da migração do sal.

A utilização da junção e análise dos refletores sísmicos permite capacitar e melhorar a comparação dos dados e, portanto, interpretar em conjunto tendências geométricas das unidades sísmicas em diferentes bacias e em diferentes intervalos de tempo geológico.
\end{abstract}

1 Universidade Privada de Angola; Angola; jose_cumbo@yahoo.com.br

2 Dep. Ciências da Terra e Centro de Geociências, Faculdade de Ciências e Tecnologia da Universidade de Coimbra, 3000-272 Coimbra, Portugal; penareis@dct.uc.pt 
Palavras-chave - Bacia Lusitânica; Bacia de Peniche; Controlo estrutural; Linha sísmica

Abstract - The Atlantic marginal basins in the Portuguese offshore include the Lusitanian Basin and the Peniche Basin. The Lusitanian Basin outcrops and therefore the available information is abundant. The knowledge of the Peniche Basin is limited to some published seismic lines (ALVES et al., 2006). The working method consisted in measuring the thicknesses of the different seismic units with an increasing distance to the structural elements considered to have controlled the sedimentation. The data shows that the Cretaceous units in the Lusitanian Basin seem to be less influenced by the salt and fault activity than the equivalent of the Peniche Basin. On the contrary, in the upper Jurassic in the Lusitanian Basin, units show a stronger control by the structure. In the Peniche Basin, the lower Jurassic units show an evident structural control. The used method allows a better comparison and interpretation of the seismic data.

\section{Keywords - Lusitanian Basin; Peniche Basin; Structural control; Seismic line}

\section{1 - Introdução}

\section{1 - Enquadramento geológico e objetivos}

O conjunto das bacias marginais do Atlântico Norte situadas no onshore e no offshore português inclui, entre outras, a Bacia Lusitânica (onshore e offshore raso) e a Bacia de Peniche (offshore profundo) (Fig. 1). Na margem conjugada norte-americana situam-se no off-shore canadiano, as Bacias dos Grand Banks (Jeanne D'Arc e Flemish) (vd. PIMENTEL et al., 2007). Todas estas bacias foram geradas na sequência da fragmentação da Pangea no Triásico (PENA DOS REIS \& PIMENTEL, 2010).

A Bacia Lusitânica, com alongamento NE-SW, situa-se na fachada ocidental da Península Ibérica, frente ao Oceano Atlântico. Corresponde à uma bacia periatlântica, originada num contexto com influência tetisiana, partilhando, por isso, com ambos os oceanos, alguns dos controlos e características tectonossedimentares. Contém um preenchimento sedimentar com espessuras muito variáveis e superiores a $5 \mathrm{Km}$ nas suas áreas depocêntricas, apresentando um registo desde o Triásico superior até ao Cretácico superior, (PENA DOS REIS \& PIMENTEL, 2010). A Bacia de Peniche, cujo registo geológico apenas se conhece por algumas linhas sísmicas, apresenta um conjunto de semi-grabens com geometrias de crescimento sintectónico, e está separada da Bacia Lusitânica por um alto de soco conhecido como o Bloco das Berlengas.

No registo mesozóico da Bacia Lusitânica onshore identificam-se cinco grandes etapas que possuem uma clara correspondência com fases de estruturação do Atlântico. Estas etapas estão registadas pelas seguintes sequências limitadas por descontinuidades: UBS1 Triásico superior - Caloviano; UBS2 - Oxfordiano - Berriasiano; UBS3 - Valanginiano - Aptiano inferior; UBS4 - Aptiano superior - Campaniano inferior; UBS5 - Campaniano superior - Maastrichtiano (PENA DOS REIS et al., 1992). Apesar do detalhe acima referido, o conhecimento atualmente existente das bacias da margem portuguesa é muito desigual. Com efeito, se a Bacia Lusitânica aflora em grande parte e, por isso, a informação acumulada é muito vasta, já a Bacia de Peniche é apenas conhecida através de algumas poucas linhas sísmicas publicadas (ALVES et al., 2006), cuja interpretação não pode ainda ser validada, pela inexistência de dados de perfuração. 


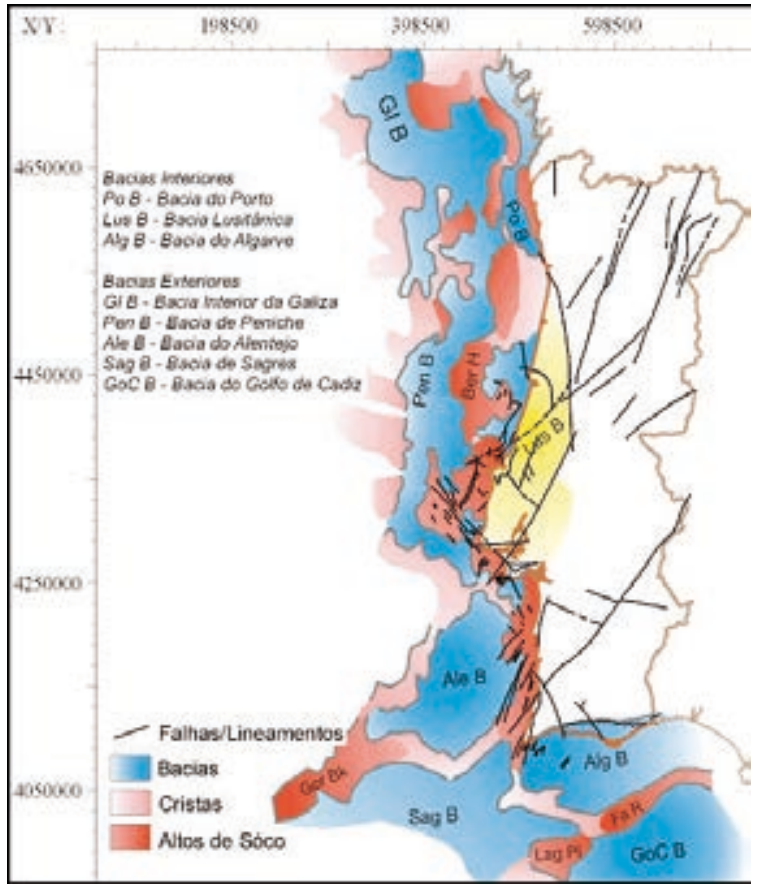

Fig. 1 - Bacias sedimentares do Atlântico relacionadas com a margem atlântica portuguesa (DGEG, 2012).

As unidades sísmicas interpretadas e publicadas mostram configurações bastante contrastadas, tendo em conta as idades admitidas, bem como as distâncias observáveis relativamente a elementos estruturais relevantes, tais como falhas normais e anticlinais, normalmente associados a empolamentos salinos. A relação interpretada com os referidos elementos estruturais permite estimar os episódios durante os quais estes exerceram maior influência durante a acumulação das diferentes unidades sísmicas.

O presente trabalho tem como finalidade documentar, interpretar e discutir aspetos relevantes da estratigrafia sísmica em três áreas selecionadas das Bacias Lusitânica e de Peniche, com recurso à caracterização e discussão dos principais refletores sísmicos e do seu significado no reconhecimento da influência da tectónica na sedimentação e na configuração geométrica das unidades sísmicas estudadas.

\section{2 - Metodologia}

A análise da estratigrafia sísmica de setores da Bacia Lusitânica e da Bacia de Peniche, fez-se com base em exemplos publicados. Nas linhas sísmicas e respetivas superfícies estratigráficas interpretadas por vários autores, foram efetuadas, em cada unidade sísmica selecionada, mediçóes de espessura em intervalos regulares, a partir de estruturas maiores, cuja influência na sedimentação é tida como provável (núcleos de domos salinos, falhas 
maiores, etc.) (CUMBO, 2011). Os dados obtidos foram representados em gráficos cartesianos. Admite-se que, a existir uma relação de contemporaneidade entre os elementos estruturais e a sedimentação das unidades na sua proximidade, essa relação terá expressão nas mudanças de espessura, já que esses elementos estruturais condicionam geralmente o valor da subsidência/soerguimento e, portanto, da acomodaçáo.

\section{2 - Áreas de estudo: bacias lusitânica e de Peniche}

A Bacia Lusitânica (Fig. 2) tem cerca de $300 \mathrm{~km}$ na direção Norte-Sul e de $150 \mathrm{~km}$ na direção Este - Oeste, incluindo a sua parte emersa (AZERÊDO et al., 2003; PENA DOS REIS et al., 2007) e apresenta uma área aproximada de $22.000 \mathrm{Km}^{2}$. É delimitada a Este, pelo fragmento soerguido do soco hercínico, que se designa por Maciço Hespérico, e a Oeste, o limite físico da Bacia Lusitânica é representado pelo horst do soco aflorante na Berlenga e Farilhôes, o chamado "Bloco das Berlengas" que a separa da Bacia de Peniche (WILSON et al., 1989).

A evolução tectónica da Bacia Lusitânica foi condicionada por falhas que se formaram durante o episódio da fraturação tardivarisca aproximadamente entre os 300 e os $280 \mathrm{Ma}$. Este episódio tardiorogénico resulta de imposição de regime de cisalhamento direito à microplaca Ibérica nos seus paleolimites E-W setentrional e meridional, dos quais resultariam as falhas de desligamento esquerdo de direção aproximada NNE-SSW a NE-SW (RIBEIRO, 2002). Outras falhas orogénicas variscas de orientação N-S (Falha de Porto-Tomar) e NW-SE foram também importantes na estruturação da Bacia Lusitânica (KULLBERG et al., 2006). Durante o Mesozóico as estruturas com direção NE-SW e NNE-SSW tiveram um comportamento dominantemente distensivo. Todavia, a partir do final do Cretácico, mas principalmente durante a orogenia Bética, a Placa Ibérica sofreu uma deformação compressiva N-S, que teve como principal consequência a progressiva inversão do eixo central da bacia ao longo de falhas oblíquas, soerguendo e exumando, em particular, as espessas séries do Mesozóico (PENA DOS REIS \& PIMENTEL, 2006)

Estas orientaçôes estruturais encontram expressão nas bacias em análise e condicionam as configuraçôes resultantes do controlo exercido pelas falhas sinsedimentares através designadamente de geometrias de crescimento nos enchimentos dos blocos subsidentes e das rotas da migração salina.

Para testar e ilustrar o método atrás descrito, selecionaram-se as linhas sísmicas S84 23 (cfRASMUSSEN et al., 1998), AR5-81 (cfALVES et al., 2003) e a linha E-W na Bacia de Peniche (cf. ALVES et al., 2006).

\section{1 - Análise da linha sísmica S84-23 (Bacia Lusitânica; offshore de Figueira da Foz)}

Esta linha na Bacia Lusitânica alonga-se segundo a orientação SW-NE na região a sudoeste da Figueira da Foz (Fig. 2; A) e é balizada por três poços no offshore raso (Fa-1, 13C-1 e Mo-1). 

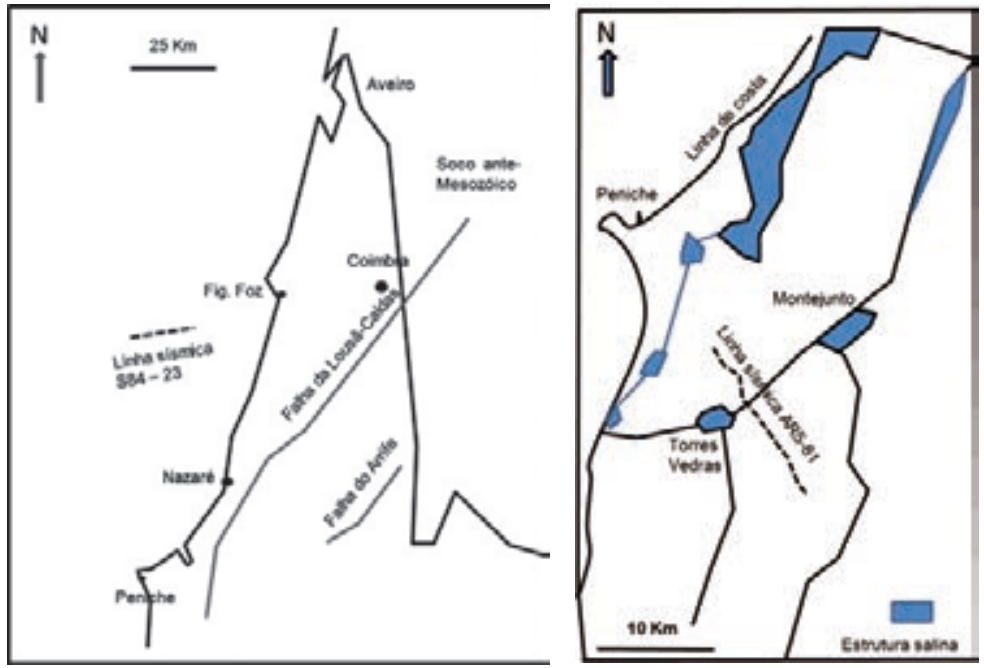

Fig. 2 - Mapas simplificados com a localização das linhas sísmicas da Bacia Lusitânica analisadas neste trabalho; A - Linha S84-23; B - Linha AR5-81.

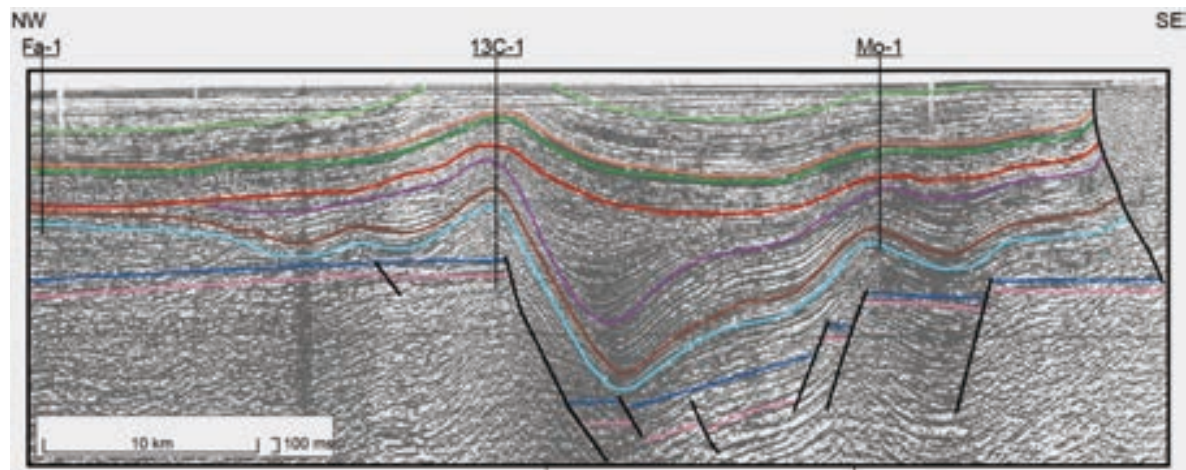

Fig. 3 - Linha sísmica S84-23 (RASMUSSEN et al., 1998).

A falha de referência situa-se imediatamente a SE do poço 13C-1.

Tabela 1 - Unidades sísmicas da linha S84-23 e códigos de cores dos respetivos limites estratigráficos (RASMUSSEN et al., 1998).

$\begin{array}{cccccc}\begin{array}{l}\text { Unidades } \\ \text { Sísmícas } \\ \text { Cores }\end{array} & \text { Sinemuriano } & \begin{array}{c}\text { Jurássico infe- } \\ \text { rior e médio }\end{array} & \begin{array}{c}\text { Jurássico } \\ \text { superior }\end{array} & \begin{array}{c}\text { Cretácico } \\ \text { inferior }\end{array} & \begin{array}{c}\text { Cretácico } \\ \text { superior }\end{array} \\ & & & & \end{array}$


A linha sísmica S84-23 (Fig. 3) póe em evidência a existência duma falha importante com orientação provável NW-SE e pendor acentuado para SE, que foi usada como estrutura de controlo das unidades sísmicas reconhecidas, e definindo um semi-graben entre os poços 13C-1 e Mo-1.

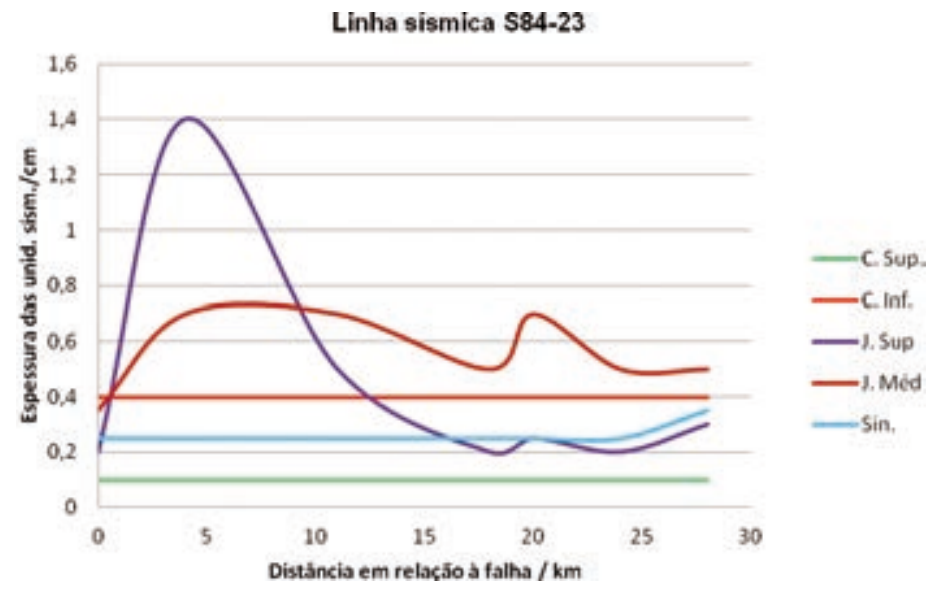

Fig. 4 - Linha sísmica S84-23. Curvas da variação de espessura das unidades sísmicas interpretadas relativamente à falha $(0,1 \mathrm{~cm}=100 \mathrm{~m})$.

A análise das figuras 3 e 4 mostra que a unidade sísmica Sinemuriano apresenta pouca variação da sua espessura, não tendo sido significativamente condicionada pela falha de bordo do graben. As unidades sísmicas do Jurássico médio e superior evidenciam variaçóes importantes na geometria e na espessura, sugerindo que a atividade sinsedimentar da falha condicionou a acumulação desses sedimentos. Presume-se que estas geometrias estão também relacionadas com a migração de massas salinas, que mostram espessuras bem diferenciadas (notem-se as espessuras abaixo da base de Sinemuriano (Fig. 3), que se presumem relacionadas com as massa salinas da Formação Dagorda). As unidades sísmicas do Cretácico inferior e superior apresentam espessuras invariantes de SE a NW, evidenciando pouca influência do funcionamento das estruturas tectónicas e da migração do sal.

\section{2 - Análise da linha sísmica AR5-81 (Bacia Lusitânica; regiáo de Montejunto)}

Esta linha localiza-se na região do alinhamento anticlinal Montejunto-Torres Vedras (onshore da Bacia Lusitânica), com orientação NW-SE, fazendo a ligação entre as sub-bacias do Bombarral e de Arruda (Fig. 2; B). A estrutura anticlinal observável apresenta uma geometria assimétrica falhada com cavalgamento para NW, evidenciando uma significativa movimentação do sal em profundidade. A interpretação publicada propóe as unidades sísmicas descritas na tabela 2.

A secção sísmica da linha AR5-81 (Fig. 5) mostra que as unidades sísmicas, em ambos os lados do anticlinal e todas do Jurássico superior, apresentam estruturas de crescimento e afilamento como resultado da influência conjugada da movimentação da falha principal e da migração salina associada. 
Tabela 2 - Unidades sísmicas da linha AR5-81 (cf. ALVES et al., 2003).

\begin{tabular}{cc} 
Unidades Sísmicas & Posição Estratigráfica \\
\hline A4 & Kimeridgiano inferior \\
A3 & Limite do Oxfordiano-Kimeridgiano \\
A2 & Oxfordiano superior \\
A1 & Oxfordiano inferior a médio \\
\hline
\end{tabular}

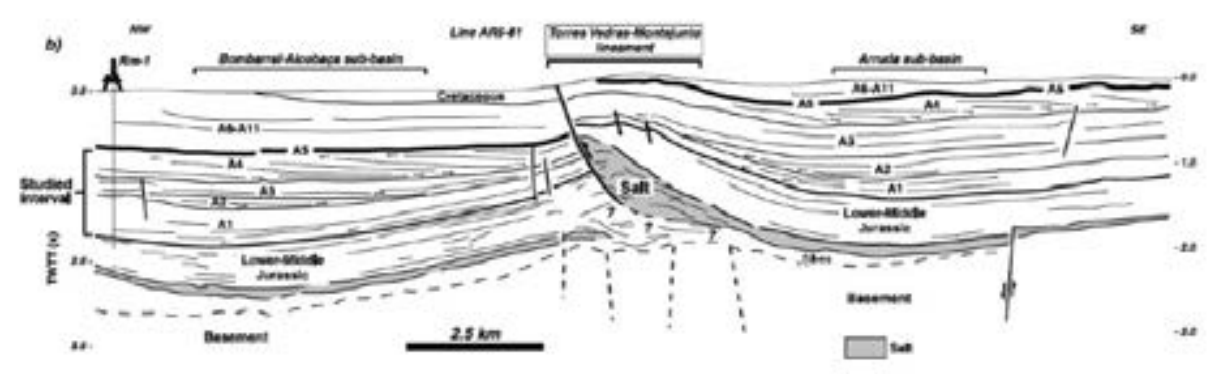

Fig. 5 - Interpretação da linha AR5-81, adquirida sobre o anticlinal de Montejunto (cf. ALVES et al., 2003) (TWTT em milissegundos).

Nota-se que as unidades sísmicas A1 a A4 são geometricamente influenciadas pela atividade coeva da falha e presumivelmente da migração salina, o que se traduz em espessuras muito diminutas junto ao anticlinal e à falha, mas que aumentam gradualmente com a distância a estas estruturas (Fig. 6). Duma forma geral, o comportamento das unidades é similar em ambos os flancos analisados, embora no flanco NW (esquerdo) se possa verificar que a unidade A2 não apresenta registo junto da falha (Fig. 6). Este facto permite supor um levantamento assimétrico mais significativo para NW, criando uma geometria de offlap no intervalo entre as unidades A1 e A2, indiciadora dum empolamento mais intenso que o processo de acumulação.

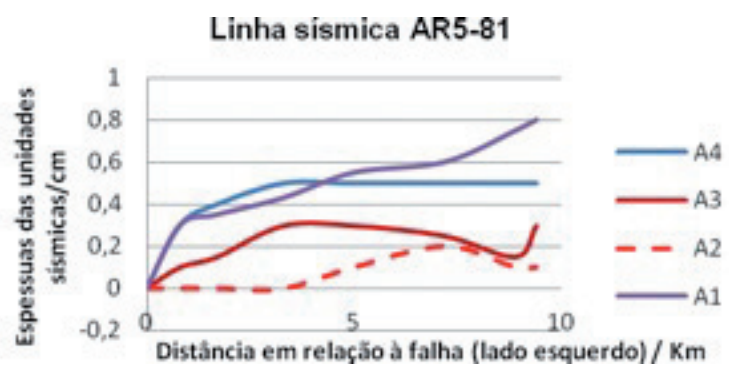

Fig. 6 - Variaçôes de espessura/distância da linha sísmica AR5-81. O anticlinal associado à falha marcada funciona como estrutura de referência $(1 \mathrm{~ms}=1 \mathrm{~cm})$. 


\section{3 - Análise da linha sísmica E-W; Bacia de Peniche}

A Fig. 7 apresenta a localização e orientação da linha sísmica analisada nesta bacia. A orientaçáo E-W interceta as estruturas dominantes do soco, alinhadas, quer de acordo com NE-SW, quer com NW-SE. A interpretação da linha proposta (ALVES et al., 2006) define um conjunto de unidades, cujas idades estão apresentadas na tabela 3.

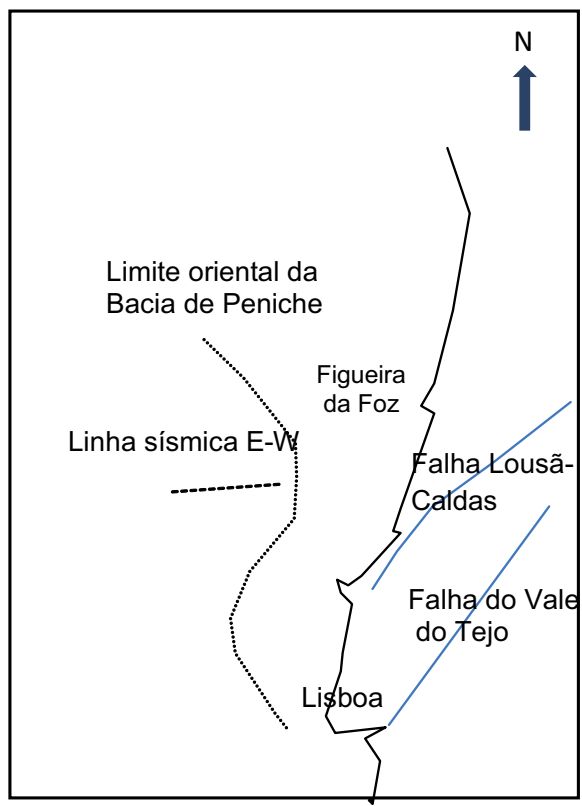

Fig. 7 - Localização da linha sísmica da Bacia de Peniche.

Tabela 3 - Unidades sísmicas interpretadas na linha E-W da Bacia de Peniche (cf. Fig. 7) (ALVES, et al., 2006).

\begin{tabular}{cc}
\hline Unidades Sísmicas & Posição Estratigráfica \\
\hline $\mathrm{C} 3$ & Miocénico inferior e médio \\
$\mathrm{C} 2$ & Eocénico médio \\
$\mathrm{K} 3 / \mathrm{C} 1$ & Limite entre Cenomaniano e Turoniano \\
$\mathrm{K} 2$ & Aptiano-Albiano \\
$\mathrm{K} 1$ & Berriasiano precoce a Valanginiano \\
$\mathrm{J} 3$ & Oxfordiano inferior \\
$\mathrm{J} 2$ & Sinemuriano \\
$\mathrm{T} / \mathrm{J} 1$ & Triásico \\
\hline
\end{tabular}

A geometria dos refletores desta linha sísmica (Figs. 8 e 9; a variação das suas espessuras, que aumentam e diminuem relativamente às posiçóes estruturais, gerando picos 
muito bem definidos) indica que as unidades sísmicas T/J1, J2, e K1 foram fortemente afetadas pelas falhas que apresentam movimentação sindeposicional. As unidades sísmicas $\mathrm{K} 2, \mathrm{~K} 3 / \mathrm{C} 1$ e C2 mostram, pelo contrário, uma reduzida influência das estruturas ativas, apresentando variaçóes pouco significativas nas suas espessuras.

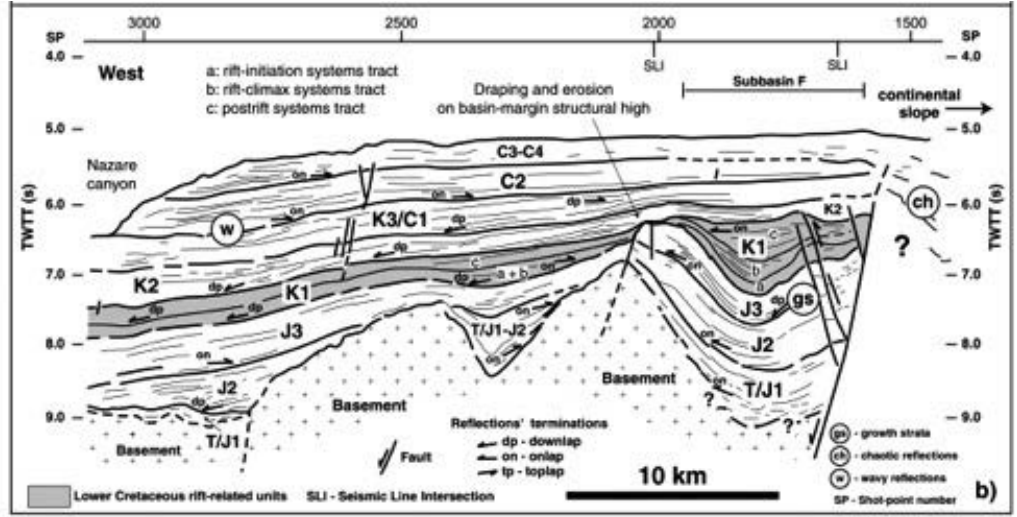

Fig. 8 - Perfil sísmico e a sua interpretação de Este - Oeste, no sector ibérico da Bacia de Peniche (ALVES et al., 2006).

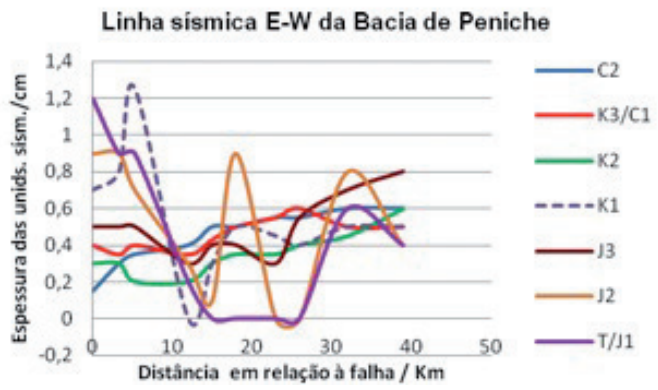

Fig. 9 - Variaçóes de espessura/distância da linha sísmica E-W na Bacia de Peniche. Sublinha-se a configuração da curva do Jurássico inferior J2, que evidencia grande controlo por parte dos elementos estruturais $(1 \mathrm{~cm}=1 \mathrm{~s}$ TWTT).

A não interpretação de evidências de acumulação e movimentação do sal nesta linha sísmica (Fig. 8) permite atribuir, apenas ao funcionamento das falhas, a configuração geométrica das unidades sísmicas identificadas.

Os refletores das linhas sísmicas do Jurássico superior da Bacia Lusitânica, contrariamente aos refletores do Jurássico inferior e médio, apresentam-se com picos muito marcantes de variação de espessuras. Pelas evidentes geometrias de crescimento visíveis, nas Figs. 3 e 5, presume-se que a atividade tectónica coeva tenha ocorrido de forma 
intensa e com a consequente migração do sal, dando lugar a geometrias onlap e toplap bem marcadas.

Para a Bacia de Peniche (Figs. 8 e 9), as unidades do Jurássico apresentam igualmente fortes indícios da influência das condicionantes tectónicas, de que são exemplos os refletores com picos muito expressivos (J2 e J3) (cf. ALVES et al., 2006). Todavia, a unidade J2 apresenta um comportamento "anómalo", aparentando uma geometria sin-rifte.

Durante o Cretácico inferior a sedimentação na Bacia de Peniche continua a ser controlada pela atividade estrutural ( $c f$. ALVES et al., 2006), apresentando-se com picos de espessura muito marcantes (Fig. 10), contrariamente ao que acontece no Cretácico inferior da Bacia Lusitânica (Fig. 4). Os elementos geométricos discutidos previamente nas duas bacias consideradas e nos casos de estudo selecionados, apresentam evidências diretas de dependência das variáveis tectónicas e, em alguns casos, da tectónica salina. Todavia, em interpretações de maior detalhe e na construção de modelos mais documentados, deve relevar-se a importância da reestruturação tardia ocorrida ao longo dos vários episódios de inversão do Cretácico superior e do Terciário.

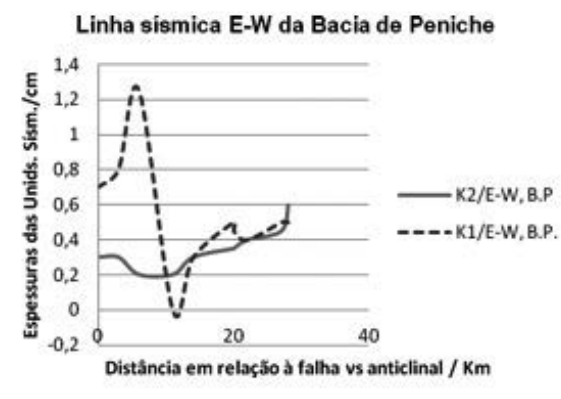

Fig. 10 - Curvas de espessura das unidades sísmicas da Bacia de Peniche (linha E-W cf. Fig. 8) durante o Cretácico inferior (K1) e o Cretácico superior $(\mathrm{K} 2)(1 \mathrm{~cm}=1 \mathrm{~s}$ TWTT).

\section{3 - Conclusóes}

1 - A comparação da configuração geométrica de várias unidades sísmicas interpretadas em linhas publicadas da Bacias Lusitânica e da Bacia de Peniche permite exprimir, com maior enfase gráfico, a provável relação existente entre as várias etapas sedimentares e o controlo exercido pela tectónica coeva seja frágil ou salina.

2 - O Jurássico inferior da Bacia Lusitânica apresenta pouca evidência de controlo estrutural, contrariamente ao que acontece com as unidades do Jurássico inferior e médio da Bacia de Peniche. Todavia, as unidades sísmicas do Jurássico médio e superior evidenciam variaçôes importantes na geometria e na espessura, sugerindo controlo por tectónica sinsedimentar

3 - As unidades sísmicas do Cretácico inferior e superior da Bacia Lusitânica apresentam espessuras invariantes de SE a NW, evidenciando pouca influência do funcionamento das estruturas tectónicas e da migração do sal. Ao mesmo tempo, na Bacia de Peniche, durante 
o Cretácico inferior, a sedimentação continua a ser controlada pela atividade estrutural ( $c f$. ALVES et al., 2006), apresentando-se com picos de espessura muito marcantes

4 - Na Bacia de Peniche, as unidades sísmicas T/J1 (Trias-Jurássico inferior), J2 (Jurássico superior), e K1 (Cretácico inferior) foram fortemente afetadas pelas falhas que apresentam movimentação sindeposicional. As unidades sísmicas K2 (Cretácico superior), K3/C1 (Limite entre Cenomaniano e Turoniano) e C2 (Eocénico médio) mostram, pelo contrário, uma reduzida influência das estruturas ativas.

\section{Referências Bibliográficas}

ALVES, T. M., MANUPPELlA, G., GAWTHORPE, R. L., HUNT, D. W. \& MONTEIRO, J. H. (2003) The depsitional evolution of diapir and fault-bounded Rift basins: examples from the Lusitanian Basin of West Iberia. Sedimentary Geology, 162, p. 273-303.

ALVES, T. M., MOITA, C., SANDNES, F., CUNHA, T., MONTEIRO, J. H. \& PINHEIRO, L. M. (2006) - Mesozoic-Cenozoic evolution of North Atlantic continental-slope basins: The Peniche basin, western Iberian margin. AAPG Bulletin, 90, p. 31-60.

AZERÊDO, A. C., DUARTE, L. V., HENRIQUES, M. H. \& MANUPELLA, G. (2003) - Da dinâmica continental no Triásico aos mares do Jurássico Inferior e médio. Cadernos de Geologia de Portugal. Instituto Geológico e Mineiro, Lisboa, p. 8-22.

CUMBO, J. M. (2011) - Estratigrafia e Interpretação Geológica de Reflectores Sísmicos do Sector Central da Bacia Lusitânica e na Bacia de Peniche (Portugal). Tese de Mestrado da Universidade de Coimbra (não publicada), $56 \mathrm{p}$.

DGEG (2012) - http://www.dgge.pt/dpep/pt/geology_pt.htm (consultado em 10 de Março de 2012)

KUllberG, J. C., ROCHA, R. B., SOARES, A. F., TERRINHA, P., REY, J., CALlAPEZ, P. \& MARTINS, L. (2006) - A Bacia Lusitaniana: Estratigrafia, Paleogeografia e Tectónica. In: (Dias, R., Araújo, A., Terrinha, P. \& Kullberg, J. C. (eds.). Geologia de Portugal no contexto da Ibéria. Univ. Évora, p. 317-368.

PENA DOS REIS, R. \& PIMENTEL N. (2006) - Curso de Campo na Bacia Lusitânica (Portugal), Roteiro. Coimbra, 88 p. (1 $1^{\text {a }}$ edição).

PENA DOS REIS, R. \& PIMENTEL, N. (2010) - IV Curso de Campo na Bacia Lusitânica (Portugal), Roteiro. Coimbra, 91p. (4a edição).

PENA DOS REIS, R., CORROCHANO, A., BERNARDES, C., PROENÇA CUNHA, P. \& DINIS, J. L. (1992) - O Meso-Cenozóico da margem atlântica portuguesa. Guias de las excursiones geológicas - III Congreso Geologico de Espańa y VIII Congreso Latinoamericano de Geologia. Ed. Universidad de Salamanca, p. 115-138.

PENA DOS REIS, R., PIMENTEL, N. \& GARCIA, A. (2007) - Curso de Campo na Bacia Lusitânica (Portugal), Roteiro. Coimbra, 154.p. (2a edição)

PIMENTEL, N., PENA DOS REIS, R., \& GARCIA, A. (2007) - The Lusitanian Basin (Portugal) and its north-american counterparts. Abstracts $1^{\text {st }}$ MAPG Conference, Marrakesh, 59 p.

RASMUSSEN, E. S., LOMHOLT, S., ANDERSEN, C. \& VEJBÆK, O. V. (1998) - Aspects of the structural evolution of the Lusitanian Basin in Portugal and the shelf and slope area offshore Portugal. Tectonophysics. 300, p. 199-225.

RIBEIRO, A. (2002) - Soft plate and impact tectonics. Springer-Verlag, Berlin, 324 p.

WILSON, R. C. L., HISCOTT, R. N., WILliS, M. G. \& GRADSTEIN, F. M. (1989) - The Lusitanian Basin of West-Central Portugal: Mesozoic and Tertiary Tectonic, Stratigraphic, and subsidence History. In: Tankard, A. J. \& Balkwill, H. R. (eds.). Extensional tectonics and stratigraphy of the North Atlantic margins, AAPG. Mem., Tulsa, 46, p. 341-361. 